\title{
STUDI VARIASI SUHU TERHADAP KUAT MEKANIK SAMBUNGAN ANTARA BAJA DENGAN TEMBAGA PADA PROSES FURNACE BRAZING
}

\author{
Bambang Waluyo Febriantoko \\ Jurusan Teknik Mesin Universitas Muhammadiyah Surakarta \\ Jl. A. Yani PO BOX 1 Pabelan Surakarta 57102 \\ Email:bambangwf@gmail.com
}

\begin{abstract}
ABSTRAK
Aplikasi furnace brazing digunakan pada pembuatan mold/dies dengan metode laminated steel tooling. Kekuatan sambungan antara logam induk dengan logam pengisi (filler) merupakan permasalahan yang utama. Kekuatan ini tergantung dari material logam induk, material logam pengisi, suhu proses brazing, tekanan proses dan metode brazing. Penelitian ini menyelidiki variasi suhu proses furnace brazing antara logam induk baja mild steel dengan logam pengisi tembaga.

Metode penyambungan antara mild steel dengan baja dilakukan dengan menggunakan jig untuk memberi tekanan selama proses brazing. Jig berikut dengan spesimen uji tarik, uji geser, dan uji belah dilakukan pemanasan didalam furnace serta didinginkan dengan perlahan setelah mencapai suhu penelitian. Pengujian mekanis dilakukan dengan mesin Universal Testing Machine.

Hasil penelitian menunjukkan semakin tinggi suhu brazing akan didapatkan kekuatan yang semakin naik, namun suhu maksimum tergantung dari titik leleh logam pengisi.
\end{abstract}

Kata kunci : Brazing, Kuat Mekanik, Baja, Tembaga

\section{PENDAHULUAN}

Penyambungan pada logam dengan logam lain dilakukan dengan banyak cara, diantaranya dengan las, lem, solder, baut, paku keling dan brazing. Brazing salah satu cara penyambungan yang banyak dilakukan untuk menyambung plat tipis yang tidak mungkin digunakan metode las. Pada pembuatan dies/mold dengan metode rapid prototyping dengan menggunakan cara Laminated Steel Tooling (LST) maupun layer manufacturing brazing banyak memegang peranan yang penting. Metode LST mengunakan plat baja yang disusun tiap layer dengan menggunakan brazing maupun lem untuk menyambung tiap layer plat. Kekuatan sambungan antara baja dan tembaga sebagai logam pengisi inilah yang akan dibahas pada penelitian ini dengan memvariasikan suhu pada proses brazing didalam furnace.

\section{TINJAUAN PUSTAKA DAN DASAR TEORI}

Dalam usaha untuk mengaplikasikan pendinginan conformal, laminasi brazing bahan Aluminium yang dilakukan dengan memberikan filler ditengahnya dan diberi tekanan selama pemanasan pada suhu $610^{\circ} \mathrm{C}$ selama 1 jam telah terjadi diffusion bonding yang erat sehingga air pendingin tidak masuk ke dalam mold (Himmer dkk, 1999). Uji coba pada bahan mild steel dilakukan oleh peneliti dengan cara meode brazing mild steel dan Tembaga pada suhu $1110^{\circ} \mathrm{C}$ 
dengan waktu tahan di dalam furnace selama 30 menit (Wimpeny dkk, 2003). Bryden dkk, (2001) melakukan brazing bahan mild steel dengan filler Ag-Cu-Zn-Sn pada tekanan 1,7 MPa dengan suhu $720^{\circ} \mathrm{C}$. Yoon \& Na (2003), melakukan penelitian pembuatan Rapid Lami-nated Tooling dengan membandingkan proses brazing dengan solder mendapatkan bahwa metode brazing mempunyai kekuatan yang lebih tinggi.

Brazing merupakan metode penyambungan dua logam dengan menggunakan filler pengisi dengan cara pemanasan dibawah suhu melting logam pengisinya. Proses brazing dilakukan dengan ciri: komposisi logam filler pengisi untuk brazing selalu berbeda dengan komposisi logam induk, kekuatan sambungan brazing ini selalu dibawah kekuatan logam induk, melting point dari filler brazing selalu lebih rendah dari logam induk, metode perekatan dari dua logam ini dengan cara difusi atom (De Garmo dkk, 1984).

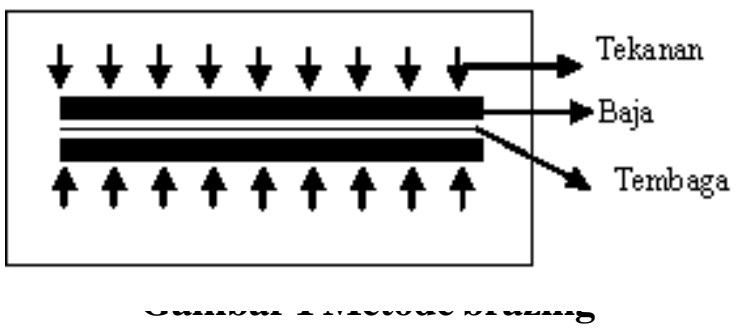

Metode perekatan ini dapat dilihat pada Gambar 1, filler pengisi berada ditengah dan dijepit oleh logam induk. Tekanan diberikan pada kedua sisi dan dilakukan pemanasan di dalam furnace beserta dengan jignya.

Pemanasan dengan temperatur yang tepat akan menjaga kwalitas brazing, temperatur terlalu tinggi membuat filler meleleh, jika temperatur terlalu rendah maka kekuatan sambungan akan menurun (Wimpeny dkk, 2003).

Difusi merupakan perpindahan atom dari satu tempat ke tempat lainnya. Tipe dari difusi material solid yaitu : self diffusion dan interdiffusion. Self diffusion adalah perpindahan atom pada satu jenis bahan. Interdiffusion adalah perpindahan atom antara dua atau lebih jenis bahan yang berbeda.

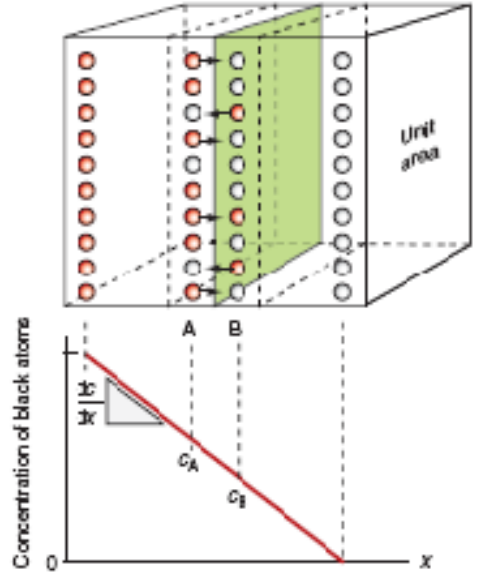

\section{Gambar 2 Mekanisme interdiffusion, (Ashby, 2007)}

Mekanisme terjadinya difusi terbagi oleh: difusi vacancy dan difusi interstitial.

Difusi Vacancy adalah mekanisme perpindahan atom karena ada kekosongan tempat. Kekosongan ini akan diisi oleh atom yang lain, seperti pada Gambar 3

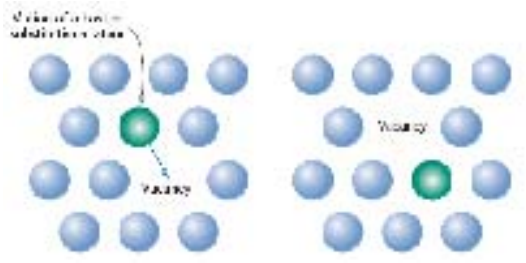

\section{Gambar 3 Mekanisme difusi Vacancy (Callister, 2007)}

Difusi interstitial adalah mekanisme perpindahan atom karena gerakan atom didalam rongga atom, diilustrasikan pada Gambar 4.

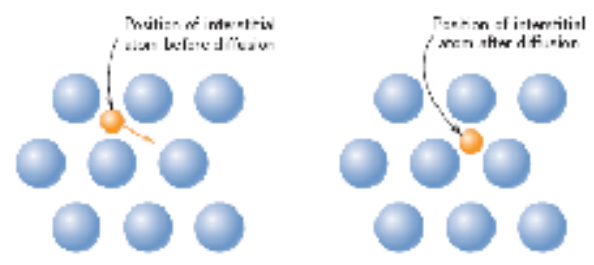

Gambar 4 Mekanisme difusi Interstitial (Callister, 2007) 
Pemodelan teori difusi berdasarkan oleh jumlah flux yang berdifusi ke logam lain. Flux dapat dijelaskan pada Gambar 5, yaitu perpindahan atom persatuan luas.

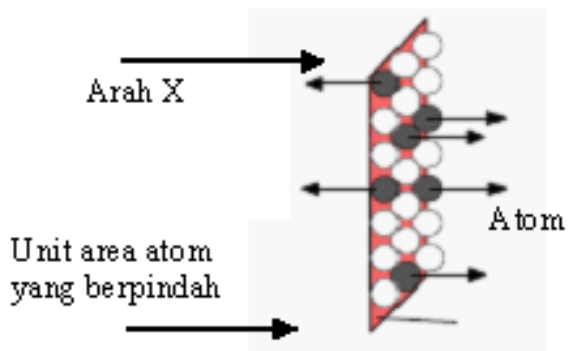

\section{Gambar 5 Mekanisme perpindahan atom}

Persamaan perhitungan flux $(\mathrm{J})$ adalah

$\mathrm{J}=\frac{1}{\mathrm{~A}} \frac{\mathrm{dM}}{\mathrm{dt}}$ atau $\left[\frac{\text { atom }}{\mathrm{m}^{2} \mathrm{~s}}\right]$

dengan $\mathrm{J}$ adalah flux, A adalah luas area yang terdifusi.

Perhitungan fluk difusi (J) menurut persamaan dari hukum Fick's pertama kondisi satu dimensi adalah :

$$
J=-D \frac{d C}{d x}
$$

dengan D merupakan koefisien difusi, $\frac{\mathrm{dC}}{\mathrm{dx}}$

merupakan gradien konsentrasi bahan (massa / volume dibagi dengan jarak).

Hubungan antara koefisien difusi dengan temperatur digunakan persamaan :

$\mathrm{D}=\mathrm{Do} \exp \left(-\frac{\mathrm{Q}}{\mathrm{RT}}\right)$

dengan Do adalah pre exponential dari bahan, Q adalah energi aktivasi, R merupakan konstanta gas, dan T adalah temperatur.

Hubungan antara kekuatan sambungan dengan difusi yang terjadi dipengaruhi oleh jumlah flux (jumlah atom per satuan luas). Sedangkan tegangan tarik $(\sigma)$ pada kekuatan sambungan adalah : dengan $\mathrm{P}$ adalah gaya tarik, A adalah luas area penyambungan.

Sehingga semakin besar jumlah flux dari filleryang terdifusike dalam logaminduknya maka akan semakin besar pula tegangan tariknya.

Untuk tegangan geser (ô) pada kekuatan sambungan dapat dirumuskan :

$$
\tau=\frac{\mathrm{P}}{\mathrm{A}}
$$

dengan P adalah gaya geser, A adalah luas area penyambungan

Sedangkan tegangan tarik (ó) karena pembelahan (cleavage) pada kekuatan sambungan adalah :

$\sigma=\frac{\mathrm{P}}{\mathrm{A}}$

dengan $P$ adalah gaya tarik yang mengakibatkan pembelahan, A adalah luas area penyambungan.

\section{METODE PENELITIAN}

Perekatan brazing dilakukan dengan menggunakan jenis filler sesuai pada Tabel 1 yaitu Tembaga. Kondisi variabel ketiga jenis proses brazing dapat dilihat pada Tabel 1. Brazing pada filler Tembaga proses penyam-bungannya diberi tekanan 1,7 MPa (Bryden, 2001) di dalam jig. Jig beserta dengan spesimen dipanaskan pada furnace dengan variasi suhu $1000^{\circ} \mathrm{C}, 1050^{\circ} \mathrm{C}$, $1100^{\circ} \mathrm{C}$ ditahan selama 30 menit (Wimpenny, 2003) dan didinginkan perlahan di dalam furnace (lihat Gambar 10). Setiap variasi suhu digunakan spesimen sebanyak 5 buah, kemudian dilakukan pengujian tarik, geser dan belah.

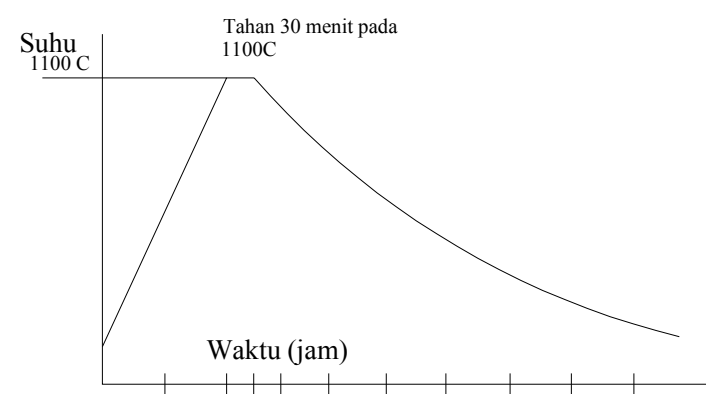

\section{Gambar 6 Grafik perlakuan brazing Tembaga $1100^{\circ} \mathrm{C}$ dalam furnace}


Tabel 1 Variabel perekatan brazing

\begin{tabular}{|c|c|}
\hline \multirow{2}{*}{$\begin{array}{c}\text { Suhu }\left({ }^{\circ} \mathrm{C}\right) \\
\text { pemanasan }\end{array}$} & Jenis Filler \\
\cline { 2 - 2 } & Tembaga \\
\hline Waktu tahan & 30 menit \\
\hline Tebal filler & $0,17 \mathrm{~mm}$ \\
\hline Tekanan pres & $1,7 \mathrm{MPa}$ \\
\hline $\begin{array}{c}\text { Metode pengha- } \\
\text { lusan permukaan }\end{array}$ & $\begin{array}{c}\text { Kertas gosok } \\
\text { ukuran } 120-1000\end{array}$ \\
\hline
\end{tabular}

\section{BAHAN DAN SPESIMEN}

\section{Bahan}

Material yang digunakan sebagai basis laminasi menggunakan mild steel dengan ukuran sesuai Gambar 7, Gambar 8, Gambar 9. Hasil uji komposisi kimia pada material adalah $98,52 \mathrm{Fe}, 0,473 \mathrm{C}$, 0,55 Mn, 0,232 Si. Bahan perekat (filler) yang digunakan adalah tembaga dengan komposisi $99 \%$.

\section{Spesimen}

Pembentukan spesimen untuk uji tarik mengacu pada standart ASTM D897 dengan bentuk sesuai Gambar 7, untukuji belah (cleavage) mengacu pada standart ASTM D1062 dengan bentuk sesuai Gambar 8, untuk uji geser sesuai dengan standart ASTM D1002 sesuai dengan Gambar 9. Standar uji ini mengacu pada pengujian adhesive bonding karena akan dibandingkan dengan hasil pengujian penyambungan lem epoxy.
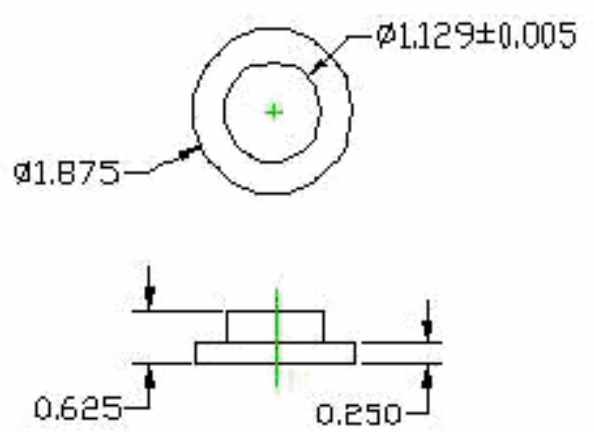

Gambar 7 Bentuk spesimen uji tarik ASTM D897 (Material Testing Technology Co, 2003.)

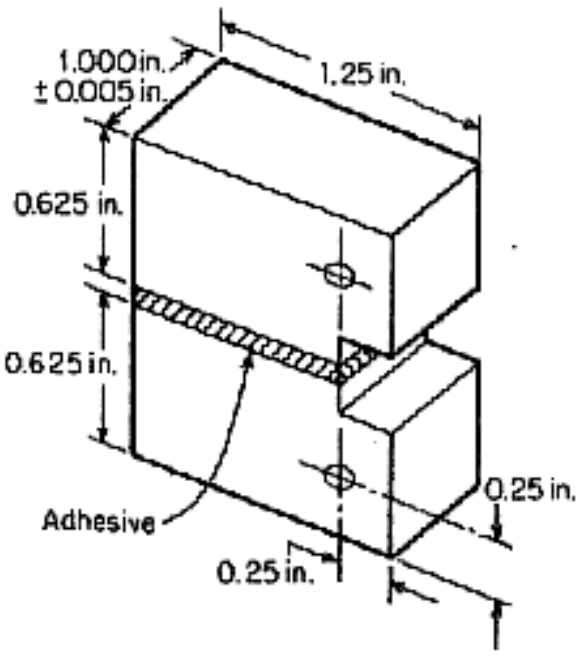

Gambar 8 Bentuk spesimen uji belah (cleavage) ASTM D1062 (Harper, 1996)

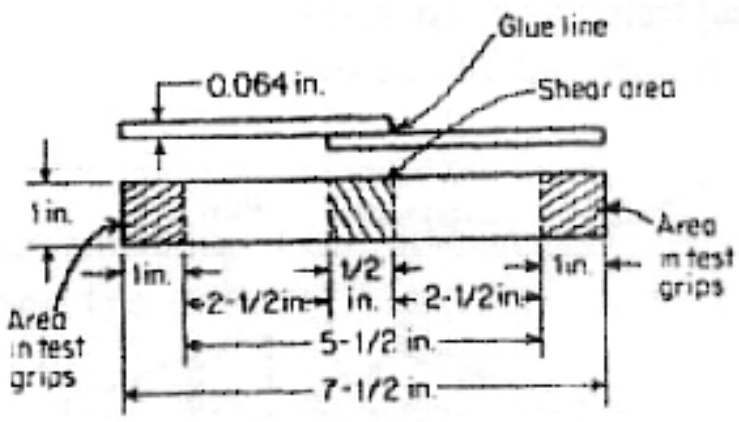

\section{Gambar 9 Bentuk spesimen uji geser ASTM D1002 (Harper, 1996)}

\section{Alat Penelitian}

Penelitian dilakukan dengan menggunakan peralatan:

1. Universal Testing Machine merk Shimadsu Servo Pulser kapasitas 20 ton di Laboratorium Teknik Mesin UGM

2. Furnace merk Thermolyne dengan suhu maksimum $1400^{\circ} \mathrm{C}$ di Laboratorium Teknik Kimia UMS

3. Alat pres \& jig buatan sendiri

4. Torsi meter merk Britool kapasitas $70 \mathrm{~N} / \mathrm{m}$ digunakan untuk mengatur tekanan pada jig 


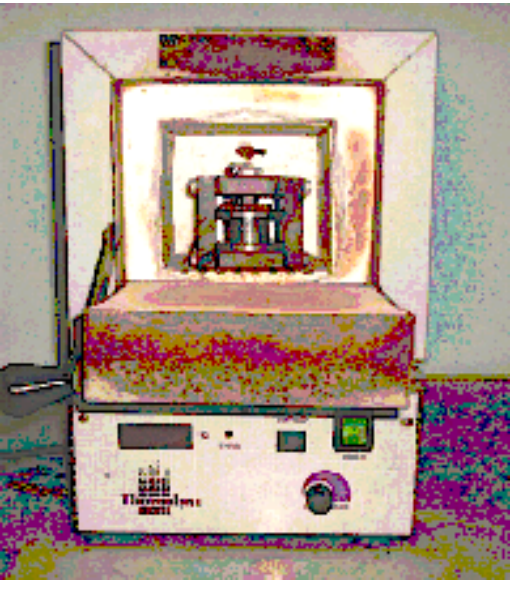

Gambar 10 Furnace

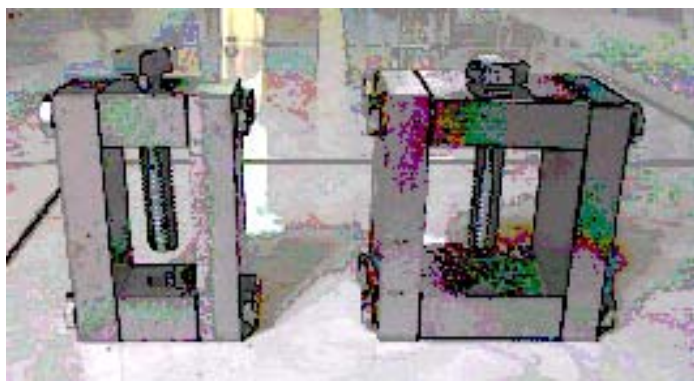

Gambar 11 Jig

\section{HASIL PENELITIAN}

\section{Pengujian Geser}

Hasil pengujian geser metode brazing dapat dilihat di Gambar 12. Hasil pengujian geser brazing filler Tembaga lokal suhu furnace $1000^{\circ} \mathrm{C}$ sebesar $21,39 \mathrm{MPa}$, suhu $1050^{\circ} \mathrm{C}$ sebesar 22,56 MPa, dan suhu $1100^{\circ} \mathrm{C}$ sebesar 29,61 MPa. Hasil Patahan berupa patah getas. Pada pengujian ini didapatkan hasil tertinggi pada filler Tembaga pada suhu $1100^{\circ} \mathrm{C}$ dengan kekuatan sebesar 29,61 MPa. Bryden (2001) melakukan laminasi mild steel ketebalan $1,6 \mathrm{~mm}$ dengan filler Ag 56, Cu 22, Zn 17, Sn 5\% pada $720^{\circ} \mathrm{C}$ didapatkan kekuatan geser sebesar 28,75 MPa.

Bentuk penampang potong pada Gambar 13, 14, dan 15 setelah pengujian, terdapat perbedaan luas penampang potong. Pada Gambar 15 luas bidang penampang lebih besar dari gambar sebelumnya, hal ini menunjukkan bahwa semakin tinggi suhu akan didapatkan luas penampang bidang kontak semakin besar.

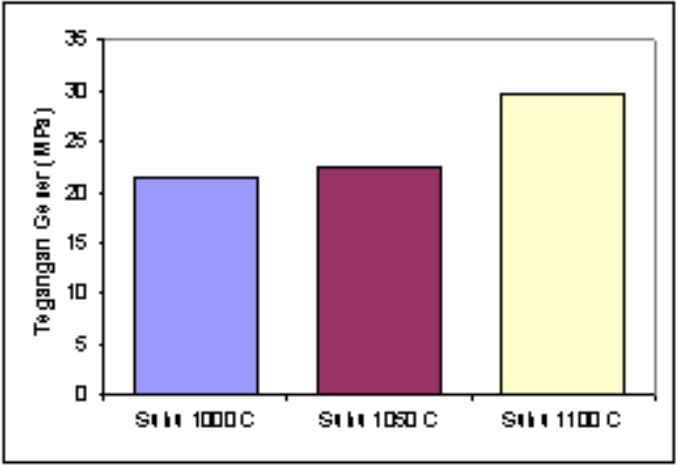

\section{Gambar 12 Diagram batang pengujian geser brazing}

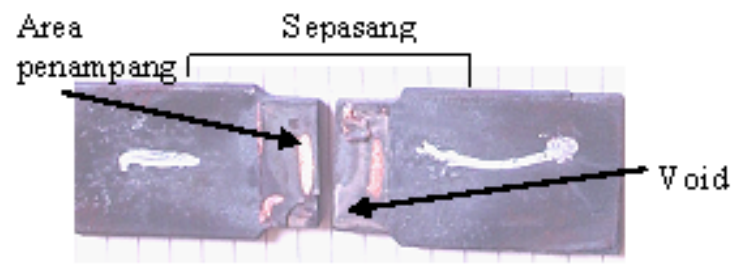

\section{Gambar 13 Penampang uji geser suhu 1000C}

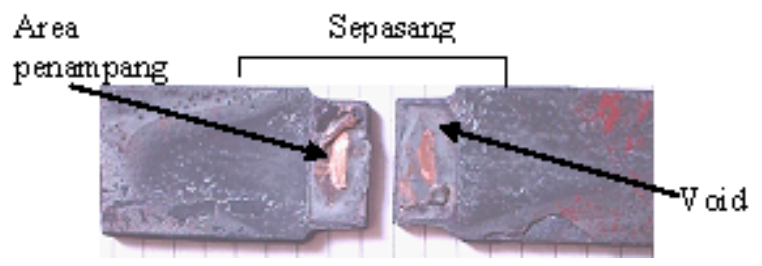

\section{Gambar 14}

Penampang uji geser suhu 1050

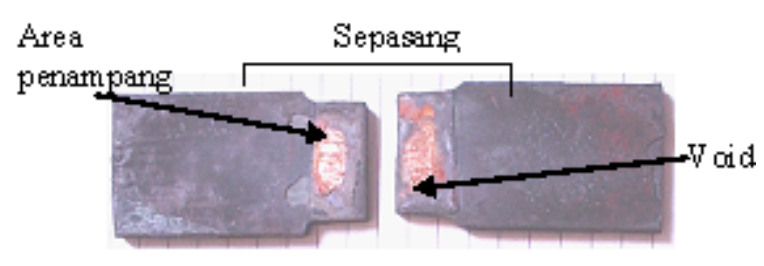

Gambar 15

Penampang geser suhu $1100{ }^{\circ} \mathrm{C}$ 


\section{Pengujian Tarik}

Hasil pengujian tarik metode brazing dapat dilihat di Gambar 16. Hasil pengujian tarik brazing filler Tembaga lokal suhu furnace $1000^{\circ} \mathrm{C}$ sebesar $17,91 \mathrm{MPa}$, suhu $1050^{\circ} \mathrm{C}$ sebesar 8,4 $\mathrm{MPa}$, dan suhu $1100^{\circ} \mathrm{C}$ sebesar $25,16 \mathrm{MPa}$.

Pengujian tarik brazing Tembaga didapatkan hasil tertinggi pada variasi suhu $1100^{\circ} \mathrm{C}$, terdapat penurunan yang signifikan antara hasil pada suhu $1000^{\circ} \mathrm{C}$ dan $1050^{\circ} \mathrm{C}$. Penurunan ini dapat disebabkan oleh bidang kontak permukaan yang tidak rata antara filler dan logam induk.

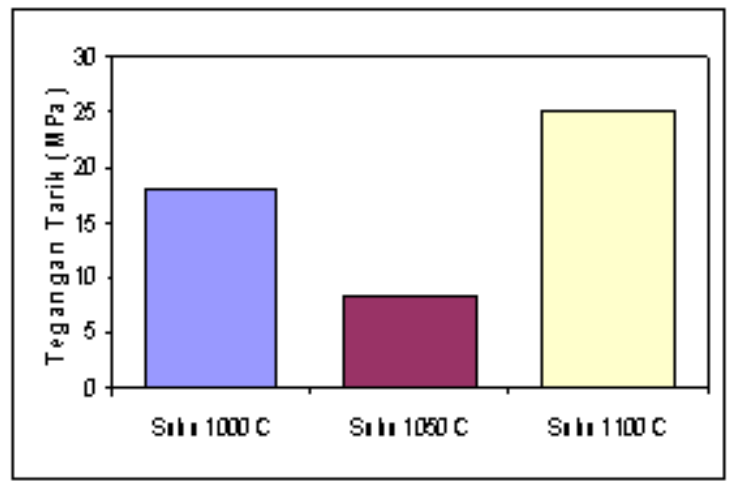

\section{Gambar 16 Diagram batang pengujian tarik brazing}

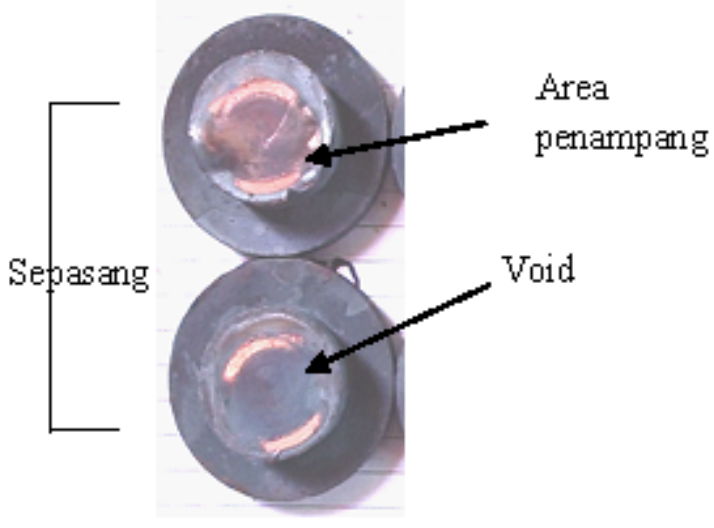

\section{Gambar 17 \\ Penampang uji tarik suhu $1000{ }^{\circ} \mathrm{C}$}

Penampang potong pada Gambar 4.19, setelah dilakukan pengujian pada suhu $1100^{\circ} \mathrm{C}$ terlihat bahwa luas bidang potong lebih besar dari yang lainnya. Gambar 17 penampang potong

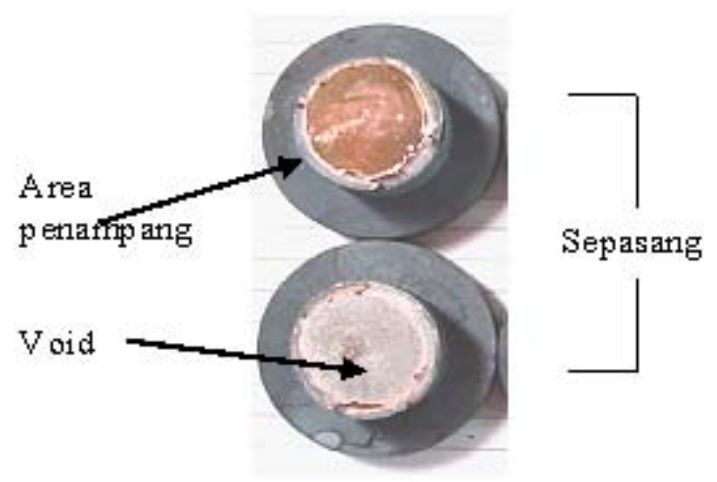

Gambar 18

Penampang uji tarik suhu $1050^{\circ} \mathrm{C}$

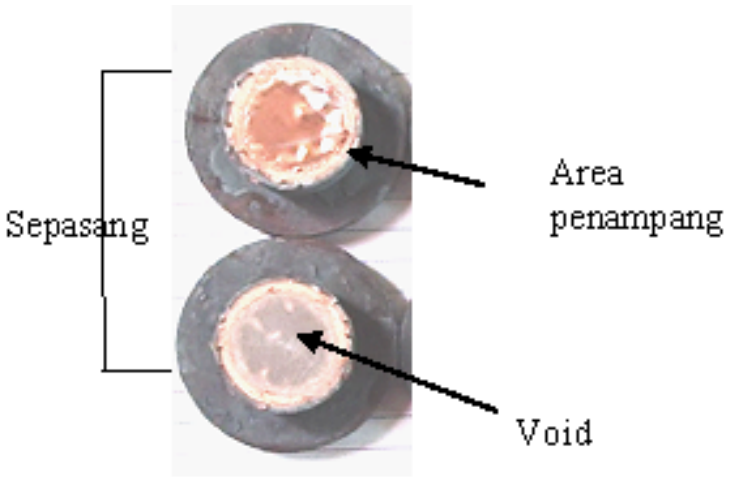

Gambar 19

Penampang uji tarik suhu $1100{ }^{\circ} \mathrm{C}$

dari yang lainnya. Gambar 17 penampang potong suhu $1000^{\circ} \mathrm{C}$ lebih besar dibandingkan suhu $1050^{\circ} \mathrm{C}$ yang diikuti pula dengan naiknya kekuatan tariknya, hal ini dapat disebabkan masalah kerataan permukaan.

\section{Pengujian Belah (Cleavage)}

Hasil pengujian belah metode brazing dapat dilihat di Gambar 20. Hasil pengujian belah brazing filler Tembaga lokal suhu furnace $1000^{\circ} \mathrm{C}$ sebesar $5,75 \mathrm{MPa}$, suhu $1050^{\circ} \mathrm{C}$ sebesar $11,05 \mathrm{MPa}$, dan suhu $1100^{\circ} \mathrm{C}$ sebesar 15,67 MPa. Hasil patahan berupa patah getas.

Pengujian belah dengan filler Tembaga didapatkan hasil tertinggi pada suhu $1100^{\circ} \mathrm{C} \mathrm{se-}$ besar 15,6 MPa (pada Gambar 20). Nilai kekuatan brazing filler Tembaga naik seiring dengan naiknya suhu pada furnace proses brazing. 


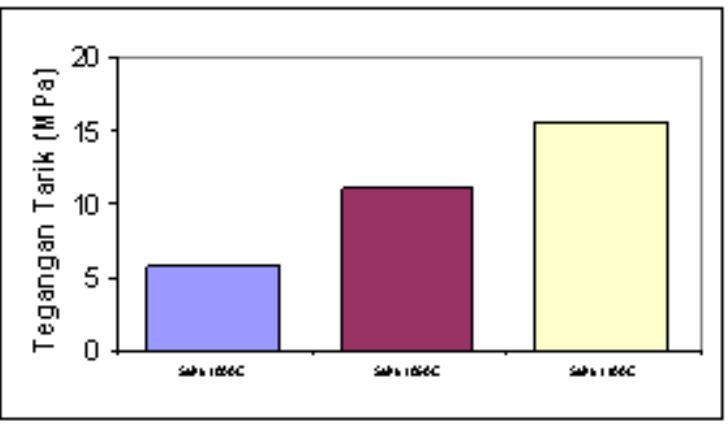

Gambar 20 Diagram batang pengujian belah brazing

Penampang uji belah dapat dicermati pada Gambar 21, Gambar 22, Gambar 23. Disini terdapat perbedaan luas area kontak permukaan pada variasi berbagai suhu. Pada suhu $1000^{\circ} \mathrm{C}$ kontak permukaan lebih kecil dibandingkan dengan suhu $1100^{\circ} \mathrm{C}$ yang mempunyai luas bidang kontak yang lebih besar.

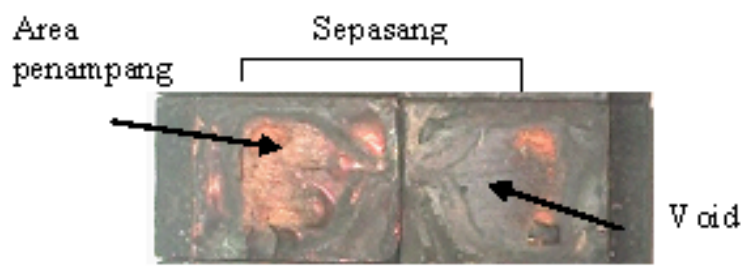

Penampang uji belah suhu $1000^{\circ} \mathrm{C}$
Area

penampang

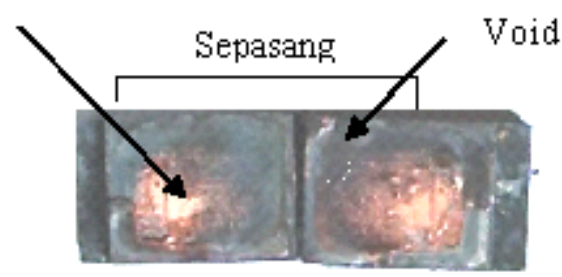

Gamoar $\angle \angle$

Penampang uji belah suhu $1050^{\circ} \mathrm{C}$

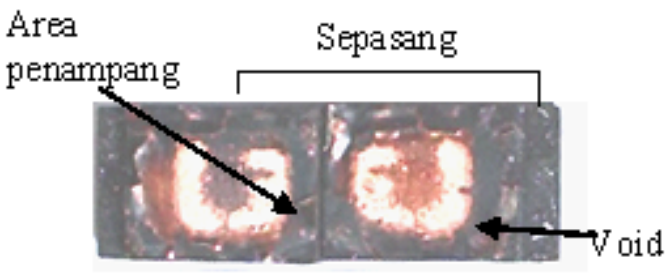

Gambar 23

Penampang uji belah suhu $1100^{\circ} \mathrm{C}$

\section{KESIMPULAN}

Kekuatan mekanis pada sambugan baja dengan baja menggunakan tembaga sebagai logam perantara didapatkan pengaruh suhu terhadap kekuatan sambungan, semakin tinggi suhu brazing akan semakin kuat sambungannya. Suhu maksimum proses brazing sampai $1100^{\circ} \mathrm{C}$.

\section{DAFTAR PUSTAKA}

Bryden, B.G., Pashby, I.R, 2001, Hot Platen Brazing to Produce Laminated Steel Tooling, Journal of Material Processing Technology 110 206-210

Bryden, B.G., Pashby, I.R, Wimpenny, D.I, Adams, C., 2000, Laminated Steel Tooling in Aerospace Industry, Material and Design 21 403-408

De Garmo, P., Black, J.T., Kohser, R.A., 1984, Materials and Processes in Manufacture, Seventh Edition, Maxwel Macmillan

Himmer, T., Nakagawa, T., Anzai, M., 1999, Lamination of Metal Sheets, Computer in Industry 39 27-33

Mueller, B.dan Kochan, D., 1999, Laminated Object Manufacturing for Rapid Tooling and Pattermaking in Foundry Industry, Computers in Industry 39 47-53 
Muller, H. dan Sladojevic, J. 2001, Rapid tooling approaches for Small lot Production of Sheet metal parts, Journal of Material Processing Technology 115 97-103

Rabinkin, A., Wenski, E., Ribaudo, A., 1998, Brazing Stainless Steel Using a New MBF-Series of Ni-Cr-B-Si Amorphous Brazing Foils, Welding Reseach Supplement, P 66s-75s.

Wimpenny, D.I., Bryden, B., Pashby, I.R., 2003, Rapid Laminated Tooling, Journal of Material Processing Technology 138 214-218

Ashby M., Shercliff H., Cebon D., 2007, Material Engineering Science Processing and Design, Butterwoth-Heinemann, UK

Callister W.D., 2007, Material Science \& Engineering, Seventh Edition, John Willey \& Sons

Yoon S. H., Na S.J., 2003, Rapid LaminationTooling by Brazing \& Soldering Process, Journal Of Manufacturing Process, Volume 5 No 2 